\title{
EQUITY RETURNS AND INTEGRATION: IS EUROPE CHANGING?
}

\author{
KPATE ADJAOUTÉ \\ HSBC Private Bank (Suisse) SA and FAME \\ JEAN-PIERRE DANTHINE \\ HEC-University of Lausanne, CEPR, and FAME
}

This paper analyses the consequences of the process of financial and economic integration on European equity markets. It documents significant changes in 'fundamentals', notably an increased synchronization of macroeconomic activities, and a non-negligible evolution in pricing, with a decrease in the cost of capital and converging equity premiums. As to equity returns themselves, in the face of what could turn out to be long-run upward trends in the correlations among both country and sector returns and a narrowing of the superiority of country factors, the benefits to be gained from finding diversification opportunities at a more disaggregated level appear to be higher than ever.

\section{INTRODUCTION}

How significant is the mark left by the all-important process of economic and financial integration, including the advent of the euro, on equity markets? From the viewpoint of equity investors, can one assert that the promises of European integration are materializing? Our strategy to shed light on these questions is to analyse sequentially the effects of economic and financial integration on the fundamentals being priced in European financial markets (section II) and on the characteristics of the pricing mechanism (section III), before turning to the observations that can be made on equity returns themselves (section IV). Section V summarizes the answers we provide to these questions.

\section{FUNDAMENTALS}

Can we trace the impact of the process of economic and financial integration in Europe on

\footnotetext{
${ }^{1}$ This paper was preceded by and builds on Adjaouté and Danthine (2001, 2003, 2004), as well as Adjaouté et al. (2000) and Adjaouté et al. (2003). Thanks are due to Sergei Sontchik for research assistance. Danthine's research is carried out within the National Center of Competence in Research 'Financial Valuation and Risk Management'. The National Centers of Competence in Research are managed by the Swiss National Science Foundation on behalf of the federal authorities.
} 
the fundamentals being priced in European equity markets? Currency unification is synonymous with full convergence of monetary policies and, in the euro area, with some degree of harmonization of fiscal policies as well. It has often been argued that the currency component in equity returns is rather minor and that the equity-pricing mechanism should be little affected by the euro. The resulting changes in the underlying (macro and micro) fundamentals could, nevertheless, have a significant impact on equity markets and this is what this section attempts to assess. With that goal in mind, we follow traditional factor asset-pricing models in viewing equity returns as being affected by a series of factors identified with the specific characteristics of the companies being priced, the industries to which they belong, and their country of origin.

At the company level, we note the growing trend toward multinational companies. Although this trend may be unrelated to European Monetary Union (EMU) and the Single Market, it is, in any case, relevant for the identification of the factors determining equity returns. In particular, one may expect that country-specific shocks will have a decreasing importance for returns, to the extent that a larger fraction of the national markets is represented by multinational companies. In the same vein, a trend towardmulti-industry firms, i.e. conglomerates, would also be relevant as it would tend to blur the lines of identification of industrial sectors as specific segments of the market capitalization. At this level, fashion comes and goes, however, and after a much criticized tendency for managers to spread their wings across industries, the current mood is to encourage firm managers to stick to their trade and to be 'focused'. Finally, growing international trade, especially to the extent that it concerns intermediate goods, de facto renders the operation and performance of a company with a given location and affiliated to a given industry more dependent on economic events originating in other countries and other industrial sectors. This set of issues bears on the task of Standard Industry Classification providers, as highlighted in Morgan Stanley Capital International (MSCI)-Standard \& Poor's joint GICS (Global Industry Classification Standard) publications. The classification of companies into given sectors proves increasingly difficult, with many business segments contributing to the turnover or the operating income, the criteria used to typify companies. Assigning a country to a company has become equally tricky, with the country of origin or the country where the company is actually headquartered often having very little to do with the geographical areas that effectively influence the business of the company.

The euro and the single market do not seem to have a specific impact on the development of industrial sectors themselves. The growing importance of services and, above all, the recent extraordinary evolution of the IT and telecommunications sectors are worth mentioning, however, as the latter, in particular, may bias the measure of the importance of the industry factor in determining equity prices and returns.

Much more is to be said of the macro environment, precisely because the underlying context of economic and financial integration, in particular the EMU and the Single Market, is likely to have a profound impact on economic structures and, of course, on macroeconomic policies.

The impact of economic development and regional integration on economic structures has been the subject of a rich literature. Most arguments support the view that the lowering of barriers to trade goods and financial assets tends to promote more specialization of national industrial structures. The first such arguments are those building on Ricardian trade theory: decreases in impediments to international trade make it possible for countries to stick to their comparative advantages. The new economic geography has emphasized the existence of pecuniary externalities associated with agglomeration as a source of geographical specialization. Monopolistic competitors tend to cluster to take advantage of these externalities, a theory for which Krugman (1991) finds support in the comparison of employment patterns in the USA (which is more specialized) and in Europe (which is less). There may be counteracting forces: a strategic objective toward diversification - so as to produce a more stable economic structure - and a taste for diversity, principally. The latter may suggest that a higher level of economic development could be associated with less specialization. At given levels of development, however, even these considerations imply that more economic integration, to the extent that it means the lowering of trading costs, and more financial 
integration, because it provides other means for diversification, should be associated with more specialization.

The diversification argument for financial integration goes as follows. Under full financial segmentation, local investors have no choice but to finance local firms and, conversely, firms depend on local investors for their financing. Limited diversification possibilities for investors mean that they will require a high compensation for holding participations in risky, undiversified firms. The cost of capital of the latter will be high. This implies that firms have an incentive to diversify on their own if they can, especially if they can do it by expanding abroadfor example, through the build-up of conglomerates or association with multinationals. This is the case even if, from a larger perspective, these attempts at diversifying at the firm level are inefficient. Similarly, within a country, one may observe the existence of productive activities which may be relatively inefficient, or for which the country may not have a comparative advantage, simply because they increase the local diversification possibilities and as a result benefit from a lower cost of capital. By contrast in an integrated financial market, there is no financial premium to industrial sectoral or geographical diversification and better specialization is affordable. Financial integration thus has the potential of changing the mix of investment projects being financed and may open the way to a higher degree of industry specialization across countries. What is the evidence? Imbs and Wacziarg (2003) show empirically that industrial concentration follows aUshaped pattern as a function of the level of economic development: after an initial development phase where agriculture takes the lion's share of resources, countries start to diversify, with labour being spread more equally across various industrial sectors. But at a later stage of development they begin to specialize again. The turning point occurs relatively late in the development process and is estimated at per-capita GDP of approximately $\$ 10,000$. They interpret their findings as resulting from the interplay of productivity increases and decreasing transport costs. The latter clearly consti- tute a force of concentration. In a Ricardian model, an increase in a country's productivity relative to the rest of the world translates into an increasing range of goods being produced domestically. The observed stages of diversification then depend on which force dominates at any given point in a country's growth path.

These effects on industry structures may, however, be offset by the convergence of macroeconomic policies that is a hallmark of EMU. With a single monetary policy, closely aligned interest rates, and fiscal policies subject to a common discipline, the macroeconomic influences on company profits and euro-wide discount factors are clearly converging. Policies and structures are thus exerting conflicting influences on the fundamentals of equities. But structural changes are expected to be slow. Moreover, there may be a ratchet effect from earlier decisions regarding localization and diversification. With fixed costs, slowly changing incentives may not lead to a reversal of previous decisions. By contrast, the effects of the coordination of macroeconomic policies are more immediate and the changes provoked by the euro are in some cases dramatic. The convergence of yields of public bonds, documented by Adjaouté and Danthine (2003) and elsewhere, is a case in point. All in all, one could thus rationalize that euro-area business cycles are becoming more as well as less synchronized. But our prior is that the effects of policy will dominate, and this is, indeed, what we find. ${ }^{2}$

Figure 1 reports the pairwise correlations of GDP growth rates across the euro area, while Figure 2 displays the time-series of the cross-sectional dispersion of the same GDP growth rates. GDP figures are collected from Datastream on a quarterly basis for each of the EMU member countries, from the first quarter of 1986 to the first quarter of 2004 . The highly changing nature of the relationships we are focusing on and the limited size of the post-euro sample of observations motivate us to complete the traditional measures of correlations with measures of dispersions. Cross-sectional dispersions are meant to be the cross-sectional counter-

\footnotetext{
${ }^{2}$ Note that, somewhat ironically, if common policies make country specificities within the euro area less prominent, they also decrease the diversification benefits brought about by financial integration. In other words, as financial integration makes diversification within the euro area increasingly easy, economic integration makes diversification inside the euro area increasingly less relevant. In that sense, there is some redundancy in economic and financial integration!
} 
Figure 1

Country Pair Correlations (GDP Growth Rate): Before and During Convergence

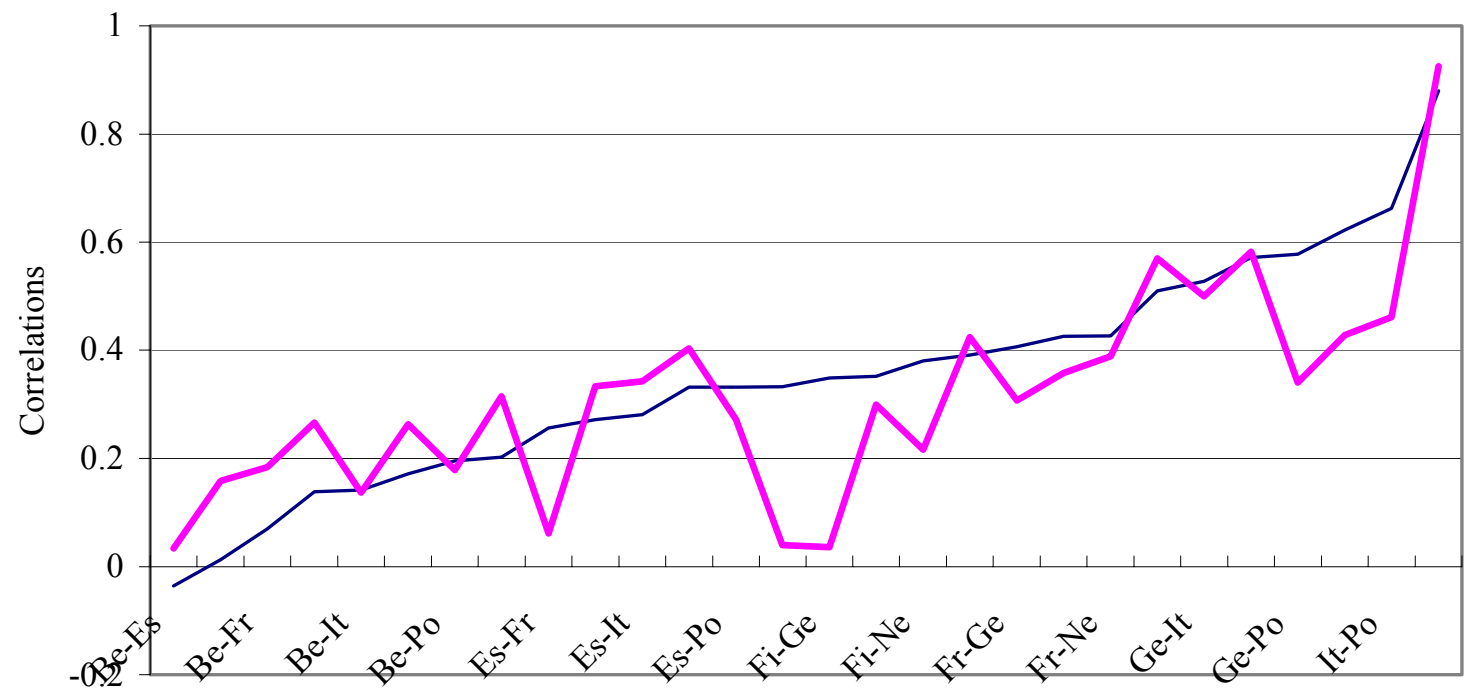

Country pairs

—Q1:1986 to Q2:1995 — Q2:1995 to Q1:2004

Source: GDP data from Datastream.

Figure 2

Quarterly GDP Growth Rate Dispersions

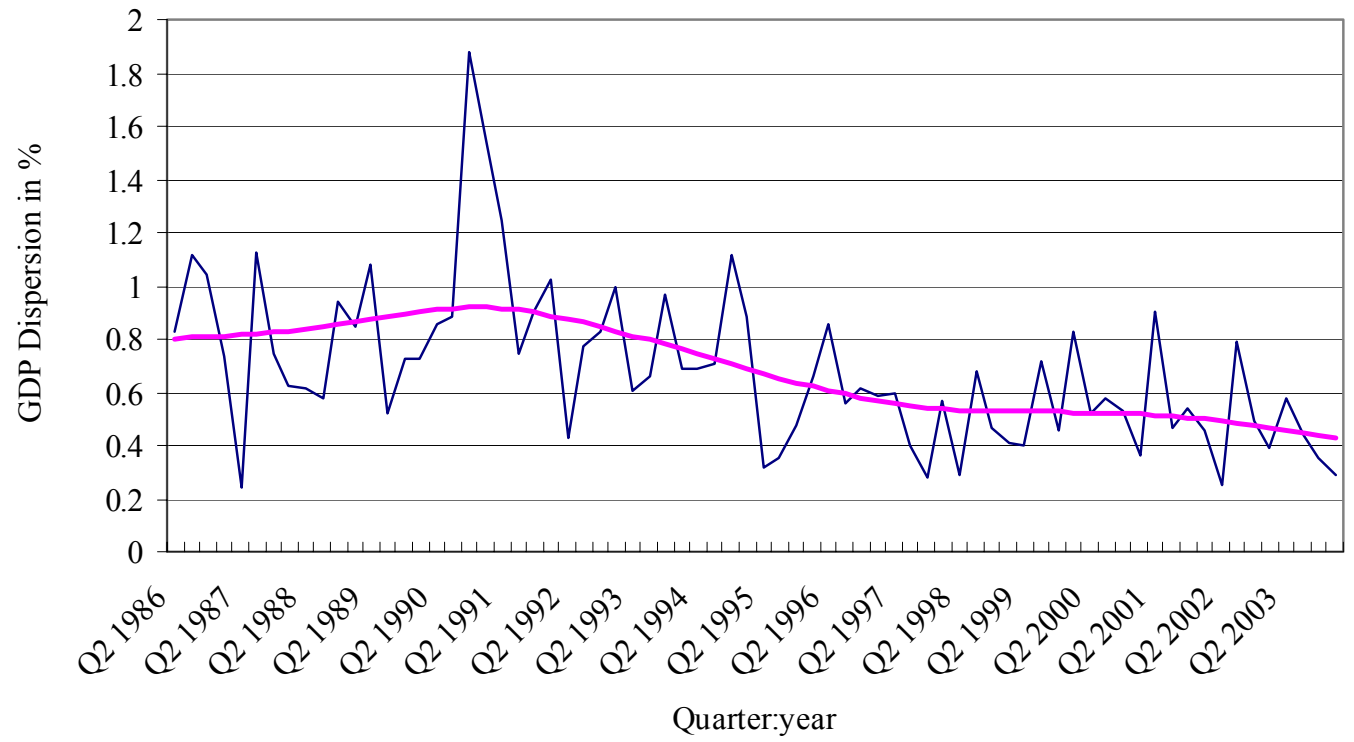

—Dispersion — Filtered_dispersion

Source: GDP data from Datastream. 
part to correlations and to provide the same underlying information. If returns or growth rates are highly correlated, we expect that more often than not they will move together on the upside or on the downside. If they do, the instantaneous cross-sectional variance of these returns or growth rates will be low. Conversely, lower correlations mean that returns/growth rates often diverge, a fact translating into a high level of dispersion. Dispersions and correlations are thus inversely related. While correlations require a minimum sample length to be estimated with some precision, no such requirement is needed for dispersions, although the measure will be more imprecise if the number of returns or growth rates entering in the variance measure is too small. Cross-sectional dispersions were first used in the context of equity returns by Solnik and Roulet (2000). As the dispersions are very noisy, we typically smooth them with Hodrick-Prescott (HP) filters to get a better idea of the underlying trends.

In Figure 1, we split our sample into two equal subperiods and compare the pairwise correlations in the first with those obtained in the second. Figure 1 does not reveal a clear aggregate pattern of increasing or decreasing correlations. If anything, those country pairs for which correlations were low during the first part of the sample turned out to be higher in the second part, and conversely. There are a few exceptions, for example Belgium/Italy and Belgium/ Portugal with low correlations remaining low, and the pairs Netherlands/Portugal, Germany/Netherlands, with high correlations getting even higher. This instability in pairwise correlations has its counterpart in the sizable volatility of the dispersions displayed in Figure 2. Here, however, a clear trend is identifiable, a trend that begins around 1991 and that persists all the way to the end of our sample. The average level of dispersion was 0.86 for the period from 1986 to 1994 and 0.51 only for the period from 1995 to 2004. There thus appears to be a remarkable evolution towards more synchronization in the business cycles (broadly defined, that is, in terms of non-detrended data, as appropriate, given the focus of our inquiry) of the euro-area countries.

Our results are in line with, and update, those obtained elsewhere in the literature with a variety of methodologies. See, among others, Agresti and Mojon (2001), Dueker and Wesche (1999), and
Ormerod and Mounfield (2002). Imbs (1999) also concludes that euro-area business cycles have moved closer together and that they are now more alike than in the immediate post-war period. His analysis is of interest (despite the absence of post-euro data) because it is centred on the estimation of Solow residuals and thus permits a finer diagnosis. $\mathrm{He}$ concludes, in particular, that supply shocks are no more synchronized between European countries than elsewhere, and that the observed evolution is due to demand factors. This strongly suggests that the higher synchronicity of business cycles indeed results from increasingly common macroeconomic policies. It is, thus, not incompatible with a simultaneous tendency towards more specialization of industrial structures, and is very much in accord with the theoretical speculations entertained earlier in this section.

\section{THE PRICING MECHANISM}

Fundamentals being priced have changed, what about the pricing mechanism? Financial integration can be defined as the law of one price applying to financial markets. Although there is a consensus that early measures of capital-market integrationthe lifting of capital controls and restriction of the free financial flows - were essential, there is also a broad agreement that full integration is far from being achieved. Is the law of one price increasingly applicable to financial assets in Europe? We pursue two tracks to get at this question. First, we look at the evidence on equity premiums. Second, we report on a more direct attempt at measuring the evolution of the stochastic discount factors (implicitly) used by European investors.

If European markets are becoming more integrated, we expect that equity risk is increasingly priced in the same way across the various European markets. Of course, the equity risk premium is an $e x$ ante context and it is difficult to uncover from historical data. We use the standard approach consisting of measuring ex post excess returns, implicitly assuming (despite obvious data limitation with the post-euro experience) that on average the ex ante premiums were confirmed.

First, let us come back to our earlier argument that financial integration renders industrial diversifica- 
tion obsolete because it improves the diversification opportunities available more cheaply with financial instruments. The consequence of this argument is that, indeed, the equity premium, or equivalently the cost of capital, should be lower, ceteris paribus. In the case of full segmentation, local investors hold undiversified portfolios (from the viewpoint of the global economy). Their reference market portfolio is limited to national firms. The appropriate measure of risk for the local country portfolio is its standard deviation. Everything else being the same, one expects that the risk premium will be high as a result of investors holding (internationally) undiversified positions. In a single financial market, by contrast, investors hold internationally diversified portfolios. The proper measure of risk for the local country portfolio is not its standard deviation, but its beta with respect to the world portfolio. There is, thus, less undiversifiable risk to be remunerated. There is, therefore, a presumption that the risk premium should be lower.

To make this concrete, let us follow Stulz (1999) and assume a simple situation where all individuals display constant relative risk aversion. The price per unit of risk is constant and identical in initially segmented markets or in the whole integrated area. Let us denote it by $P$. The reasoning above effectively states that, under segmentation, the risk premium on a given security $i$ will be $\sigma_{i}^{2} P$, where $\sigma_{i}^{2}$ is the variance and $\sigma_{i}$ is the standard deviation of the returns on asset $i$. The same asset in an integrated market will yield a risk premium of $\beta_{i} P=\rho_{i} \sigma_{i} \sigma_{m} P$, where $\beta_{i}$ is the beta of asset $i$, a function of its covariance with the market portfolio which can also be written in terms of the correlation coefficient between the market portfolio and the return on asset $i, \rho_{i}$. From this little exercise one obtains that, if the following condition is satisfied,

$$
\left[\sigma_{i} / \sigma_{m}\right]>\rho_{i}
$$

and thus, in particular, if $\sigma_{i}>\sigma_{m}$, then the risk premium in an integrated market will necessarily be smaller than in segmented markets. If this condition holds in Europe, financial integration should go hand in hand with a decrease in the cost of capital.

Of course the world is a bit more complex than the one sketched above. Degrees of risk aversion may vary from one country to the next, as well as from one period to the following (e.g. a popular assumption of habit formation implies that the rate of risk aversion fluctuates with the growth rate of consumption). As a result, under market segmentation, the price of risk may vary across countries. It will be a function of the local capital market's conditions: relative abundance of savings, relative risk appetite. With integration, the price of risk should converge. It is not impossible that the single post-integration risk premium is in fact higher for some markets. This is the case if, before integration, a given country was characterized by a relative abundance of savings, a stronger than average tolerance to risk, and/or a scarcity of risky investments to be financed. This cannot hold on average, however. For most market participants, one expects that the risk premium will be lower and more stable after integration. Moreover, integration results in the premium being increasingly impacted by common factors, including those affecting the common price of risk. One should thus expect an increasing correlation between the national equity premiums as well.

What is the evidence? Figure 3 plots the 12-month trailing standard deviation of the German equity index (MSCI indices) against the standard deviation of the MSCI EMU index. Similar results are provided in Adjaouté and Danthine (2003) for the other euro-area countries. These results are unambiguous. The EMU-wide systematic risk, as measured by the standard deviation of the MSCI EMU index, is always smaller than the corresponding measure for the national markets. The latter would be relevant in the case of full segmentation. Thus, at this first level of observation, the message is clear: an important condition for financial integration to result in a decreasing equity premium is satisfied.

Fully in line with this message, Hardouvelis et al. (2001) report that, within EU sectors, the cost of equity capital has fallen by between 0.5 and 3 per cent in the 1990s and that there is evidence of convergence in the cost of capital for similar sectors across countries (stocks in the same sector tend to have the same cost across countries). Convergence across different sectors appears to be slower, however.

Going one step further, Figure 4 displays the HP filtered equity excess returns for the EMU countries. Specifically, we have computed the excess 
Figure 3

12-month Trailing Standard Deviation

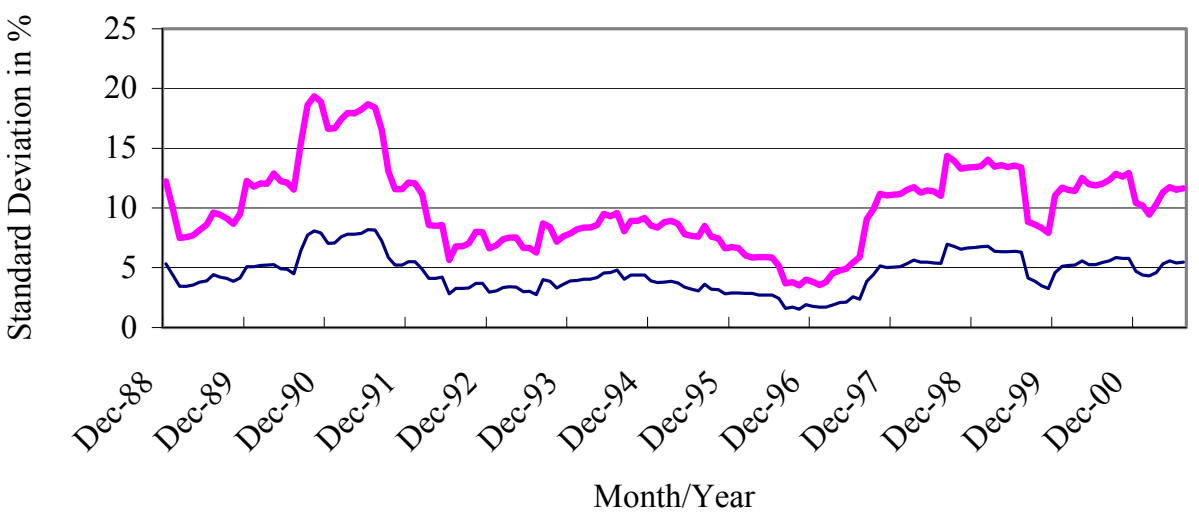

— MSCI EMU — MSCI Germany

Source: Adjaouté and Danthine (2003).

Figure 4

Filtered Equity Premiums for EMU Countries

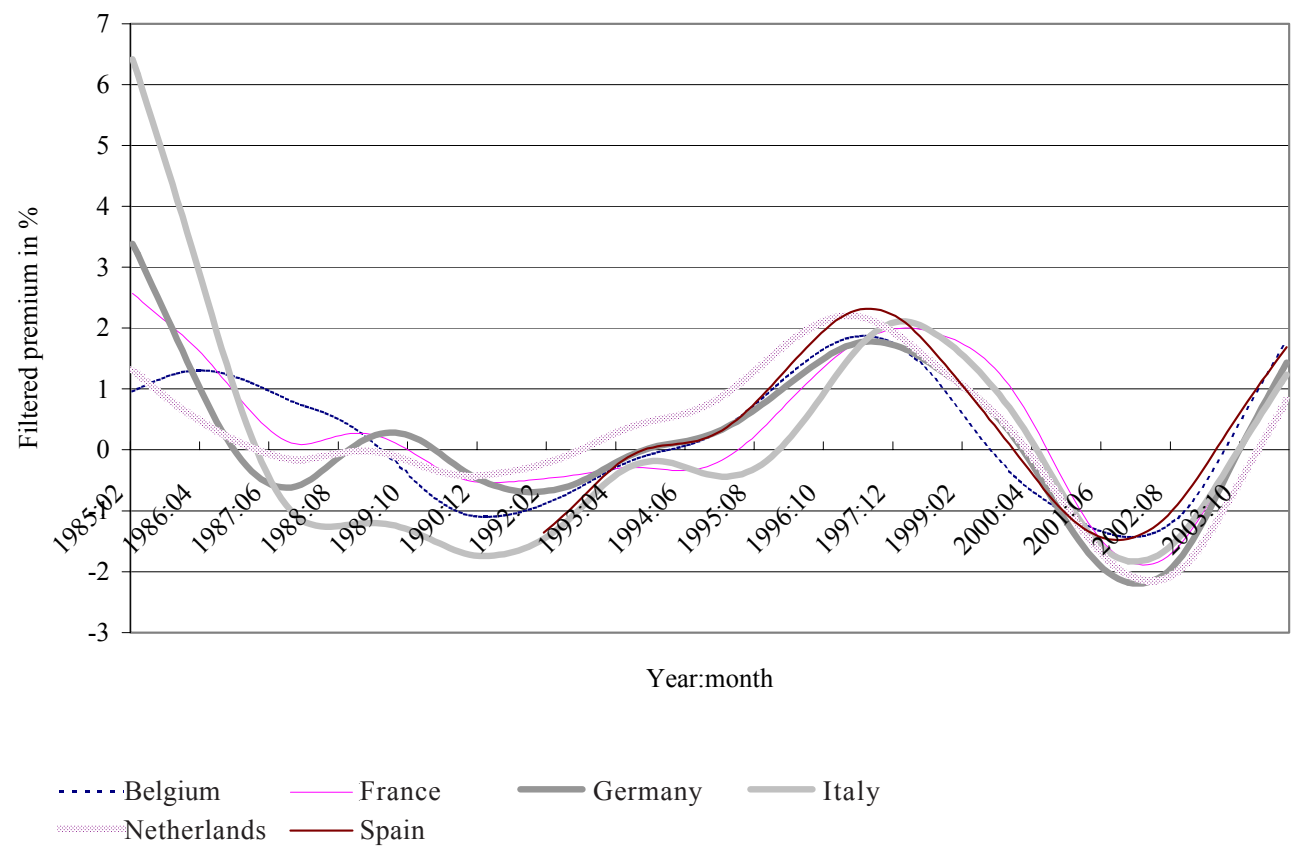

Source: Datastream.

returns as the monthly total return on national equity indices over the 1-month euro-currency return for the corresponding country. Two observations stand out. First, there is a clear convergence in excess returns up to the mid-1990s, a little-known fact that we find striking and fully in line with what we expect from the first unambiguous measures promoting financial integration. Atthis level of observation, the evidence for the second part of the 1990s is less spectacular. The severe market conditions of the end of the 1990s, where expected equity premiums have certainly not been confirmed, and the recovery of the later years are dominating the observations.

We then proceed to measure the dispersion of equity excess returns. The HP filtered series is presented in Figure 5. We find this graph particularly remarkable. It, of course, confirms the decrease in 
Figure 5

Filtered Dispersion of Equity Premiums

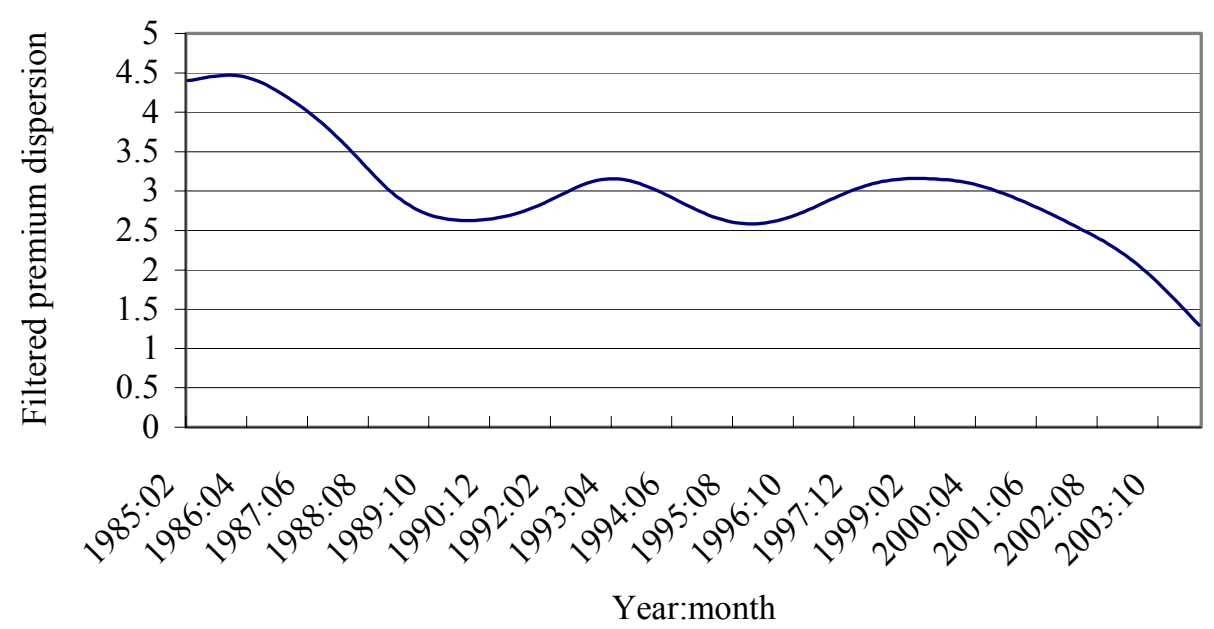

Source: Datastream.

the dispersion observed in the previous figure for the end of the 1980s. But it also suggests that, after reaching a plateau in the $1990 \mathrm{~s}$, the decrease in the equity premiums dispersion (increase in the correlation) has continued to lower levels in the beginning of the new century. The convergence of excess returns is thus being pursued with a dispersion level falling lower than the 2.5 per cent mark for the first time since the beginning of our sample (1985) in 2002 , and reaching the 1.3 per cent mark in July 2004. We need to be cautious in interpreting this result. For one thing, ex post excess returns may be a poor measure of the equity premium - a problem that is especially acute when they fall into negative territory, as they have between 2000 and 2002 . Moreover, measured excess returns are quite volatile and a longer observation period would benecessary to rule out special circumstances. Finally, the evidence on dispersion may be partly the mechanical consequence of the observation of the previous section: the fundamentals underlying the priced assets are getting increasingly similar; even if the pricing mechanism was unchanged, one should expect some convergence in the equity premiums to occur. Yet, the strong congruence between this observation and the prediction made on the consequences of financial integration for equity premiums encourages us to take seriously this additional evidence of a further increase in financial integration in Europe.

A converging assessment on the integration of European equity markets is obtained in Baele et al.
(2004, this issue). These authors conclude, in particular, that the euro-area domestic stock returns are increasingly driven by news common to all European investors and that the local return variance is increasingly explained by common European shocks. They interpret this finding as suggesting that euro-area integration of equity markets has proceeded more quickly than global equity-market integration.

The evidence on equity premiums does not distinguish pricing issues from the evolution of fundamentals (nor does the analysis of Baele et al.). To go beyond and confirm the lessons of the preceding exercise, one would need formally to test some asset-pricing model. Given the limitations of parametric asset-pricing frameworks, recent research has focused on model-free approaches to assess the extent to which stochastic discount factors have indeed converged in the EMU context. One such attempt is by Sontchik (2004), who uses an integration measure initially developed by Chen and Knez (1995). Chen and Knez's measure of integration is essentially a distance measure between two stochastic discount factors, each pricing a separate market. The smaller the distance, the more integrated the two markets are: under full integration, the same discount factor would price the two markets. The integration measure can be viewed as representing the maximum pricing error one could make if countries or industries are (wrongly) treated as fully integrated at the European level. In essence, 
defining any set of assets to be priced by no arbitrage as a market, Sontchik (2004) finds that integration has decreased since the introduction of the euro; that is, the pair-wise distance between the stochastic factors pricing individual national markets has increased, rather than decreased, in the last few years. This finding is surprising and highly counterintuitive: it is hard to conceive that financial integration has regressed and that EMU countries have become more 'segmented' after the convergence process. Our interpretation is that, at the pure pricing level, the effects of financial integration are not detectable yet, possibly because of the fragility of the statistical methods available, or because the large magnitude of the cyclical circumstances of the last few years makes it hard statistically to identify pure pricing changes. It is conceivable as well that these effects are an order of magnitude smaller than those recorded in fundamentals.

\section{RETURNS}

In this section we concentrate on equity returns themselves. In the final analysis, can we say that something has been changed at the level of ex post equity returns as a result of economic and financial integration in Europe? One of our goals is to interpret the evidence in the light of the considerations made on fundamentals and pricing in the two preceding sections.

\section{(i) The HR Approach: Country versus Sectors}

As our starting point, consider the possibility that equity returns are impacted by several (orthogonally defined) factors: sectors, countries, and global (euro area/world). ${ }^{3}$ The most celebrated version of this hypothesis was initiated by Heston and Rouwenhorst (1994, HR from now on), in which the return generating process was described as

$$
R_{i t}=\alpha_{t}+\gamma_{k t}+\delta_{j t}+\varepsilon_{i t},
$$

where $\alpha_{t}$ is the global component, $\gamma_{k t}$ is the country factor, $\delta_{j t}$ is the industry factor, and $\varepsilon_{i t}$ is the idiosyncratic return. This framework has been used in a large number of papers to investigate the issue of the relative importance of country and industry factors. In a first step, the dummy variable model is estimated, and in a second stage the relative influence of both factors is evaluated by comparing either the relative variances, or the mean average deviations (MAD) of country/industry effects. This approach is relevant here because recent research has documented changes in the relative contributions of the various factors that may be associated with the process of economic and financial integration at work in Europe.

Indeed, until recently, the literature was nearly unanimous in finding that country factors dominated industry factors. This finding was robust across different datasets. Sample papers in this vein include Beckers et al. (1996), Griffin and Karolyi (1998), and Rouwenhorst (1999). Rouwenhorst (1999), for instance, analyses the returns of all 952 European stocks included in the MSCI indices of 12 European countries. His data set ends in August 1998. With an eye on the potential impact of economic and monetary integration on the results of the variance decomposition, he concludes that the superiority of country effects has been effective at least since 1982 and that it has continued during the 19938 period 'despite the convergence of interest rates and the harmonization of fiscal and monetary policies following the Maastricht Treaty'.

The unanimity, however, appears to have broken down recently. Using more recent datasets, various studies have detected an increase in the industry effects. Arnold (2001) prolongs the study of Rouwenhorst (1999), using data up to 1999 , and finds that, in the year following the introduction of the euro, industry factors have dominated country factors. Baca et al. (2000) find that both industry and country effects have converged, while Cavaglia et al. (2000) also document that industry factors have weighed more heavily than country factors since 1997. Isakov and Sonney (2004), on the other hand, confirm the dominance of country effects for the period 1997-2000 with a sample including 20 developed countries, but they detect a shift in the last part of their sample. As shown in Figure 6, allowing for time variations in the decomposition, Isakov and Sonney confirm that industry factors are growing in importance and that they have explained a larger fraction of the variance of returns after March

\footnotetext{
${ }^{3}$ Kuo and Satchell (2001) and Hamelink et al. (2001) assume that returns are impacted by yet another factor, namely style.
} 
Figure 6

Evolution over Time of the Relative Country/Industry Influences

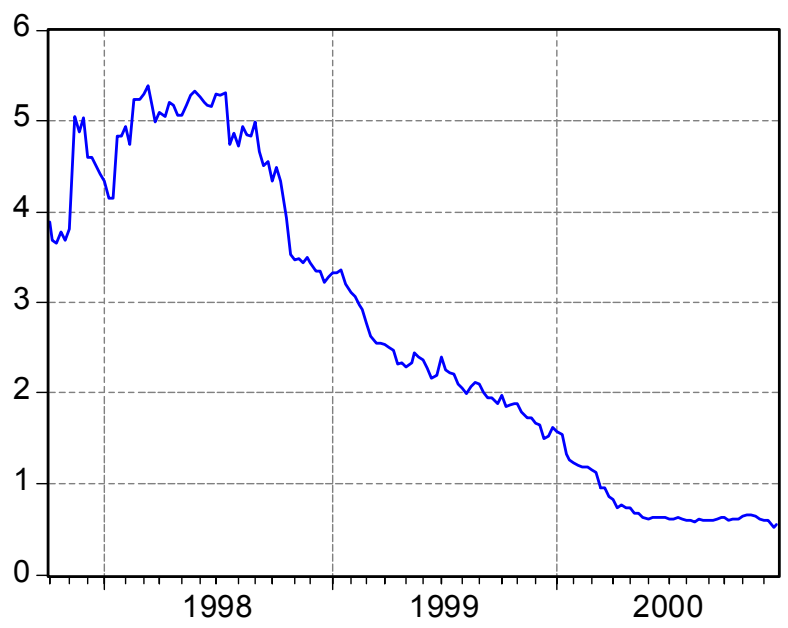

Notes: This graph represents the evolution of the ratio of the variance of the country effects to the industry effects. Variances have been estimated over 36-week intervals.

Source: Isakov and Sonney (2004).

2000. Alternative lines of research include Galati and Tsatsaronis (2001), who look at the companies in the FTSE Eurotop 300. They find that industry factors became more important than country factors for the first time a few months prior to the formal arrival of the euro. Contrary to most other researchers, however, they also find that the superiority of the country factors was insignificant after the beginning of 1996 and even as early as 1992. A possible reconciliation with Rouwenhorst (1999) arises from observing that Galati and Tatsaronis concentrate their analysis on very large capitalizations. As anticipated in our discussion on fundamentals, such stocks have been found to be less sensitive to country factors than smaller cap stocks, see, for example, Isakov and Sonney (2004).

At this stage, one may wonder whether the growing importance of sectors relative to countries is specific to the euro area, thus being plausibly associated with greater economic and financial integration, and whether it is likely to be permanent. Alternatively, one may speculate that it could be a more universal phenomenon and/or that the recent stock-market bubble could have played a role in this observation.

Brooks and Del Negro (2002a) provide interesting evidence in these regards. First, they observe that the correlation of the US equity market with other developed equity markets has moved from a low level of 0.4 in the 1980s to almost 0.9 in the late 1990s. They argue that this may be due to a decline in home bias, so that the marginal investor in the German stocks is not necessarily German and, as a result, country-specific investor sentiment now plays a minor role. Alternatively, the general rise in comovement of equity markets may be the manifestation of firms becoming more diversified internationally, and therefore increasingly exposed to the global business cycle, causing stock markets to move together more. Finally, there is the possibility that the rise in comovement of stock markets is a temporary phenomenon associated with the recent stock market boom and bust.

Brooks and Del Negro use a sample of companies representing three geographic regions, in MSCI's terminology: the Americas, Far East, and Europe. They estimate the standard dummy variables HR model and use MADs of country and sector factors to assess the relative importance of each shock. The empirical evidence for the whole sample seems to suggest that industry factors have outgrown country factors in the late 1990s, in conformity with what we reported for the euro area. However, when US stocks and companies in the telecommunications, media, biotechnology, and information technology (TMBT) sectors are excluded from the sample, the evidence of industry factors dominating country factors disappears. The absence of evidence be- 
yond TMBT sectors and the USA is interpreted by the authors as an indication that the recent dominance of industry effects over country effects is a temporary phenomenon associated with the stockmarket bubble. At the regional level, however, they report that the European evidence is not affected by the removal of TMBT sectors. Isakov and Sonney (2004) provide a converging assessment. Even when TMBT sectors are excluded from the sample, the recent superiority of sectors holds true in Europe.

To summarize, in general the estimation of the relative importance of countries and sectors is sensitive to the inclusion or exclusion of specific countries (the USA in particular) or sectors (TMBT). The fact that the evidence is more robust in the case of the euro area supports the hypothesis that something more fundamental is at work in that region.

Are these observations in accord with our understanding of the evidence on fundamentals and pricing? Let us start with pricing. As mentioned before, financial integration implies the convergence toward a single pricing kernel or discount factor. This pricing convergence affects both country and sector portfolios. Full segmentation would mean that a basket of French stocks is priced by French investors in a way that is largely disconnected with the way a basket of German stocks is priced by German investors. It also means that the German stocks in a particular industry basket would be priced via a pricing kernel that could differ and evolve differently through time from the pricing mechanism of the French stocks belonging to the same industry. The convergence of risk-free rates and of risk premiums expected under financial integration implies that, ceteris paribus, both country and sectoral baskets of stocks will have a tendency to be priced closer together. But, of course, our discussion in the previous sections indicates that the ceteris paribus does not apply. If the pricing component of equity returns converges, the objects being priced also change, potentially introducing increasing divergence in returns. Thus, in particular, if a country industrial structure becomes more specialized, the fundamentals of country indices are getting more dissimilar and returns on country indices are subject to two conflicting influences that could entail more synchronized as well as less synchronized returns. If, on the contrary, national economic structures are getting more alike, and/or if, as we have observed, the influence of increasingly common policies is the dominating factor, then indeed, both components of the pricing of country indices would display a tendency toward increasing correlation. Our reasoning thus suggests that the waning of the country factors may, indeed, be the expected consequence of economic and financial integration in Europe.

As far as sector returns are concerned, the pricing effect of financial integration should, in principle, dominate the much less clear changes in fundamentals. Financial integration should then translate into portfolios of stocks representing an industry across the geographical area being priced closer together. But short samples are a specific problem here: a specific history of sectoral shocks, leading, for instance, to a temporarily diverging performance (viz. the IT sector in recent times) may pollute our appreciation of the correlation between industry indices. Over the medium run, it is difficult to make a link between increasing financial integration and diverging sectoral returns. Note that the short sample problem also plagues the appreciation of the correlation between country returns if countries do not correspond to well-diversified portfolios of sectors. Isakov and Sonney (2004) suggest this is not the case, however.

\section{(ii) Country versus Sectors: An Alternative View}

A troubling element in the preceding discussion resides in the conflicting results reported with the HR approach. The latter appear to be very sensitive to the data used, the definition of sectors, and the period of analysis. Table 4 in Isakov and Sonney (2004), for example, shows that the ratio of the fraction of return variances explained by country and industries varies across studies in a ratio of 2 to 11.5 ! This lack of robustness may be due to several deficiencies in the HR methodology. The first problem associated with this approach is that it imposes the restriction that a firm belongs to one country and one industry only and that it is not sensitive to other countries/industries. This assumption is highly disputable in the face of the trend toward multinational firms and the reality that many firms have outputs or inputs connected with multiple industries. If the restricted HR model were true, the covariance of stock returns would show non-zero terms only for 
Figure 7

Filtered Country and Global EMU Sector Dispersions

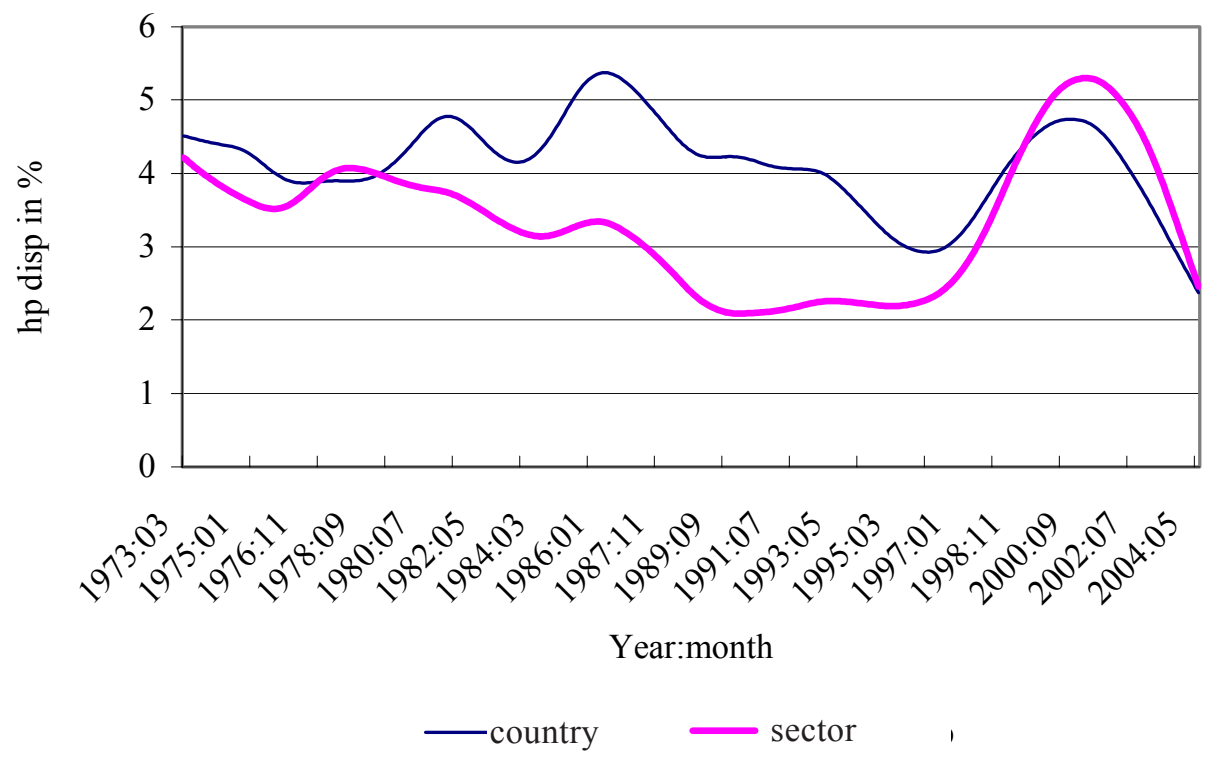

Source: Datastream.

stocks in the same sector or belonging to the same country. This is far from being the case. This is illustrated in Adjaouté and Danthine (2003) with the correlation matrix corresponding to a higher level of sector disaggregation. With 77 country sectors identified within EMU (the unit being a sector in a country), the correlation matrix includes 2,926 $(77 * 76 / 2)$ independent correlations, out of which 2,369 should be zero under the HR hypotheses. In reality, only 41 (68) of these correlations are less than 0.1 in the first (second) period covered by our sample!

A second problem associated with the HR approach is that it assumes that all stocks from the same country/industry have the same sensitivity to the country/industry factors. There are reasons to believe, however, that the exposure to a country factor may vary across firms in the same country, as some are more international than others. Brooks and Del Negro (2002b) test this hypothesis and unambiguously reject the constraints that the coefficients to own country factors are all unity.

These defects justify complementing the HR analysis with a more versatile test of the relative importance of countries versus global sectors. Figure 7 displays the Hodrick-Prescott filtered cross-sectional dispersions of country and global sector re- turns. The time series of raw country return and global sector return dispersions are highly timevarying while also following some cycles. The cyclical pattern appears clearly if one filters the series to extract their slowly moving components, as is apparent in Figure 7. This analysis is revealing. Both country and sector dispersions displayed a downward trend until the fall of 1996, an evolution that Adjaouté and Danthine (2001) credit for the widespread view that correlations among country indices were increasing in Europe owing to European integration and that, indeed, diversification opportunities were being hampered. But these dispersions have trended upward since reaching their most recent peaks around the end of 2000. By then the dispersion levels were at an all-time high for sectors and had almost matched their highest point of the mid-1980s for country indices. The movement towards lower dispersion resumed around mid-2001 and the country return dispersion series has reached its lowest level ever, while the sector dispersion series is approaching its lowest, at the end of our sample. The overall trend for country dispersion is clearly downwards; the difference between the two series has narrowed; and the sector dispersion rose above the country dispersion in around mid-1999. The two series are, however, barely distinguishable at the end of the sample. 
A number of conclusions follow. First, based on the cross-sectional dispersion of countries and sectors, the superiority of a country-based asset allocation was clear for most of the period (in conformity with Rouwenhorst (1999)). That is, as the country returns were more dispersed than the sector ones, diversification along country lines delivered higher gains. Second, the reversal taking place in early to mid-1999 confirms the reversal of the variance inequality uncovered by various authors in the HR context. ${ }^{4}$ Third, the overall tendency is consistent with the finding that the euro-area business cycles have become more synchronized, so that the orthogonal portions of the euro-area country factors are showing increasingly smaller variances. Yet, it is not true that, as often expressed, the post-euro period has been unfavourable for diversification within the euro area as the strong pick-up in both country and sector dispersions from 1996 to 1999 attests. Finally, the variability of the relationships and the fact that reversals have occurred in the past (this was the case from around 1977 to 1979) and that the current superiority of sectors may be petering out are sources of questioning. First, these facts suggest that methods, such as the HR approach, relying on time averaging over relatively long periods are vulnerable to the dating of the sample split and have a hard time identifying and dating the breaks. Second, caution should be exercised before definitively linking the latest reversal to permanent structural changes.

\section{(iii) Other Evidence on Returns}

The discussion on returns has so far been held entirely in terms of correlation/covariance matrices abstracting from the other side of the asset allocation equation - that is, from the vector of expected returns. The reason for this omission is straightforward. While there is some degree of stability in return correlations, permitting us, with caution, to approximate expected relationships with historical correlations, the same is definitely not true for expected returns. In an attempt to provide a more complete account of the observed evolutions of equity returns, Adjaouté and Danthine (2003) nevertheless conduct mean-variance optimizations on country and sector portfolios. They consider two sub-samples, the first starting in May 1987 and ending in December 1994, the second starting in January 1995 and ending in August 2002, and they allow for short selling. Focusing first on country portfolios, they find that the first-period performance of both the minimum variance and the tangent portfolios is better compared to the later period. On the other hand, when optimization is performed on the basis of sector portfolios, the performance of the minimum-variance portfolio has improved during the euro period, although the opposite is true for the tangent portfolio. Most interestingly, the Sharpe ratio of the optimal portfolios composed on the basis of sector indices is always superior to the Sharpe ratio of the optimal portfolios constructed from country indices. Proceeding with utmost caution, Adjaouté and Danthine thus conclude that if one takes on board the message from average returns, there is a distinct possibility that, for a much longer period, portfolio weights implicit in sector indices have been more conducive to portfolio performance than the portfolio weights implicit in country indices.

Recent work by Ehling and Ramos (2004) and Gerard et al. (2002) helps qualify this last statement, however. The first of these authors also propose a full mean-variance efficiency test, inspired by the work of Basak et al. (2002). When they look at the 1991-2003 period, they find that unconstrained geographic and industry diversifications are statistically equivalent, although the signs of their tests indicate that the industry efficient frontier lies outside the country efficient frontier as found by Adjaouté and Danthine. They, however, show that, once short-selling restrictions are introduced, the industry efficient frontier shrinks dramatically and lies well inside the country efficient frontier. Gerard et al. (2002) also find that industry portfolios are more strongly affected by short sales constraints than country portfolios, although, in the absence of short sales restrictions, country and industry diversifications appear as redundant strategies.

Both Adjaouté and Danthine $(2003,2004)$ and Ehling and Ramos (2004) also consider the possibility of performing mean-variance optimization at a lower level of data aggregation. This is because, while the factor analysis has a tendency to rationalize asset-allocation strategies in terms of country or industry indices, it is not clear that one can understand

${ }^{4}$ The exact dating of the reversal is likely to depend on the specific filtering or data-smoothing method. 
Figure 8

Filtered Country, Global-sector and Country-sector EMU Dispersions

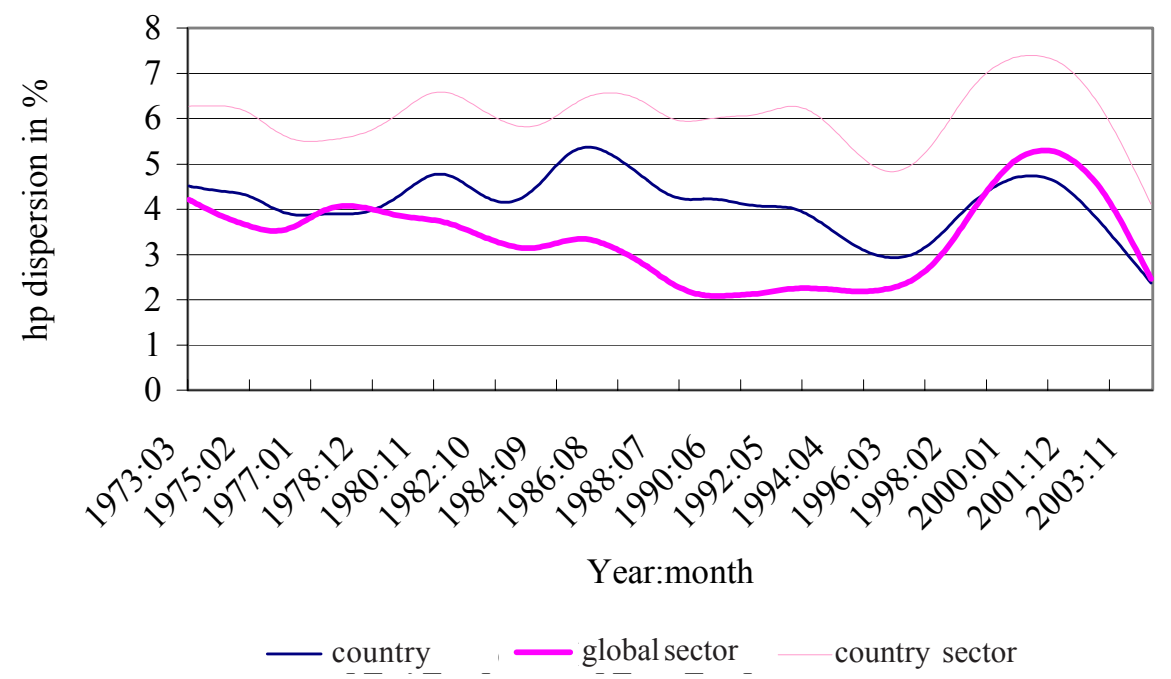

Source: Datastream.

either strategy relative to the alternative of proceeding to a full optimization across both countries and sectors. Toillustrate, why limit oneself to 10 country indices or 10 global-sector indices when one could equally well use the full $10 \times 10$ matrix of what can be labelled 'country-sector' indices? The results may be illustrated in terms of the dispersion measures reported in Figure 8 and depicting the time evolution of the country-sector dispersion along with the dispersions of country and sector returns. The lower part of the figure with the two crossing lines representing the country and global sector dispersions replicates Figure 7. The country-sector dispersion is always above these two lines and this is the striking message of this analysis. At the lower level of aggregation, the dispersion line consistently moves by a wide margin above the two others for the entire sample, i.e. 1973-2004; correlations are lower and the benefits of diversification are higher. This result, although not surprising, represents a puzzle to the extent that European asset managers appear to be torn between selecting an assetallocation model based on countries or on industries (see Adjaouté and Danthine (2003) for an elaboration) while they could significantly improve the efficiency of their portfolios by following a more disaggregated approach, diversifying simultaneously across countries and sectors. The result is not surprising in the sense that standard portfolio analysis cannot justify imposing restrictions on portfolio weights such as those in force when one is limited to either country indices or sector indices as the building blocks of asset allocation. This is confirmed by the portfolio optimization exercises of Adjaouté and Danthine (2003) and is consistent with Ehling and Ramos (2004)'s finding that a structure with a lower level of aggregation, such as country-industry pairs, clearly outperforms both industry and geographic diversifications, with or without short selling constraints. Beyond these observations, it is interesting to note that the variability of the countrysector dispersion appears to have increased recently, with both the peak of late 2000 and the current trough being unprecedented events. Unfortunately, they are both too recent for us to be able to draw any usable inference. Note, as well, that the slight downward trend in the country-sector dispersion observed in the 1990s is consistent with the long-run effect of financial integration-convergence in pricing - and with the recorded evolution of the macro fundamentals - more synchronous business cycles.

\section{v. CONCLUSIONS}

The process of financial and economic integration in Europe is manifest through significant changes in the fundamentals underlying equity markets. Of these, the most important is the increased synchronization of 
macroeconomic activities across the euro area, an evolution that is certainly due to the increased coordination of policies, but may mask a diverging evolution in industrial structures. The internationalization of corporate ownership, of the scope of corporate activities, and the increasing reliance on intra-European trade (in intermediate goods, in particular) are also relevant to the extent that they tend to blur the national and sectoral lines typically used to segment the European equity markets.

The evolution in pricing may be deemed less spectacular. It is not negligible, however. We note, in particular, that the decrease in the cost of capital and the convergence in equity premiums that are legitimately associated with financial integration appear to be materializing in Europe, although pure pricing changes are more difficult to identify statistically.

Against this background, the observations made on returns are harder to sort out. A considerable literature has focused on identifying the respective roles of country and industry factors on returns. This is understandable to the extent that the identified changes in fundamentals rationalize a diminishing role for geography and thus a relative increase in the force of industry diversification. Moreover, important changes in the organization of the industryfrom an organizational focus on countries to one that is geared toward industries - would seem to add credibility to this change. Using cross-sectional dispersions as a tool to be more precise as to the timing of changes and their persistence, we are led to exercise great caution, however. Yes, there appear to be a long-run trend towards a decrease in the dispersion of returns - that is, an increase in their correlation - for country portfolios (equity portfolios composed on the basis of country indices), but the period 1996-9 was one where these correlations were unusually low and thus geographical diversification was unusually effective. Yes, there seems to be a long-run evolution consistent with a narrowing of the superiority of country factors and even a reversal taking place in early to mid-1999. But the latest (2004) observations suggest this reversal was short-lived and they support the view that, on the basis of covariances only, a distinction between the two approaches is not warranted. Moreover, standard investment restrictions, such as short selling limits, appear to bite harder on the diversification potential of industry portfolios than is the case for country portfolios. The alleged superiority of sectoral diversification, justifying the reorganization of the industry, is thus hard to confirm. In the end, the main message emerging from the study of European equity returns may be the following: one cannot exclude that we are witnessing long-run upward trends in correlations of both country and sector returns. The existence of these trends is in accord with the evolution of fundamentals we have highlighted and with what we understand to be the consequences of integration on pricing. Confronted with this reality, the benefits to be gained from finding diversification opportunities at a more disaggregated level (at the level of country sectors) are higher than ever.

\section{REFERENCES}

Adjaouté, K., and Danthine, J.-P. (2001), 'EMU and Portfolio Diversification Opportunities', FAME Research paper No. 31 .

- _ (2003), 'European Financial Integration and Equity Returns: A Theory-based Assessment', in V. Gaspar, P. Hartmann, and O. Sleijpen (eds), The Transformation of the European Financial System, European Central Bank.

- _ (2004), 'Portfolio Diversification: Alive and Well in Euroland', Applied Financial Economics, 14, $1225-31$.

- Bottazzi, L., Danthine, J.-P., Fischer, A., Hamaui, R., Portes, R., and Wickens, M. (2000), 'EMU and Portfolio Adjustment', CEPR Policy Paper No. 5.

- Danthine, J.-P., and Isakov, D. (2003), 'Portfolio Diversification in Europe', FAME Research Paper, No. 86, forthcoming in H. Huizinga and L. Jonung (eds), The Internationalisation of Asset Ownership in Europe, Cambridge, Cambridge University Press.

Agresti, A. M., and Mojon, B. (2001), 'Some Stylized Facts on the Euro Area Business Cycle’, ECB Working Paper No. 95. 
Arnold, I. (2001), 'Country and Industry Effects in Euroland's Equity Markets', in J. Choi and J. Wrase (eds), European Monetary Union and Capital Markets, Vol. 2, Elsevier, 137-55.

Baca, S. P., Garbe, B. L., and Weiss, R. A. (2000), 'The Rise of Sector Effects in Major Equity Markets', Financial Analysts Journal, 56(October), 34-40.

Baele, L., Ferrando, A., Hördhal, P., Krylova, E., and Monnet, C. (2004), 'Measuring European Financial Integration', Oxford Review of Economic Policy, 20(4), 509-30.

Basak, G., Jagannathan, R., and Sun, G. (2002), 'A Direct Test for the Mean-variance Efficiency of a Portfolio', Journal of Economic Dynamics and Control, 26, 1195-215.

Beckers, S., Connor, G., and Curds, R. (1996), 'National versus Global Influences on Equity Returns', Financial Analysts Journal, 52, 31-9.

Brooks, R., and Del Negro, M.(2002a), 'The Rise in Comovement Across National Stock Markets: Market Integration or Global Bubble', IMF Working Paper, September.

- 0151 (2002b), 'International Diversification Strategies', IMF Working Paper, November.

Cavaglia, S., Brightman, C., and Aked, M. (2000), ‘The Increasing Importance of Industry Factors', Financial Analysts Journal, 56, 41-54.

Chen, Z., and Knez, P. J. (1995), 'Measurement of Market Integration and Arbitrage', Review of Financial Studies, 8(2), 287-325.

Dueker, M., and Wesche, K. (1999), 'European Business Cycles: New Indices and Analysis of their Synchronicity', Federal Reserve Bank of St Louis, Working Paper 1999-019B.

Ehling, P., and Ramos, S. B. (2004), 'Geographic vs Industry Diversification: Constraints Matter', FAME Research PaperNo. 113.

Galati, G., and Tsatsaronis, K. (2001), 'The Impact of the Euro on Europe's Financial Markets', BIS Monetary and Economic Department, Working Paper No. 100.

Gerard, B., Hillion, P., and de Roon, F. (2002), 'International Portfolio Diversification: Industry, Country and Currency Effects Revisited', Working Paper.

Griffin, J. M., and Karolyi, A. G. (1998), 'Another Look at the Role of the Industrial Structure of Markets for International Diversification Strategies’, Journal of Financial Economics, 50, 351-73.

Hamelink, F., Harasty, H., and Hillion, P. (2001), 'Country Sector or Style: What Matters Most When Constructing Global Equity Portfolios', FAME Research Paper No. 35.

Hardouvelis, G., Malliaropulos, D., and Priestley, R.(2001), 'The Impact of Globalization on the Equity Cost ofCapital', Banque de France, Working Paper.

Heston, S., and Rouwenhorst, K. (1994), 'Does Industrial Structure Explain the Benefits of Industrial Diversification?', Journal of Financial Economics, 36(1), 3-27.

Imbs, J. (1999), 'Technology, Growth and the Business Cycle', Journal of Monetary Economics, 44, 65-80.

- Wacziarg, R. (2003), 'Stages of Diversification', American Economic Review, 93(1).

Isakov, D., and Sonney, F. (2004), 'Are Practitioners Right? On the Relative Importance of Industrial Factors in International Stock Returns', Swiss Journal of Economics and Statistics, 140(3).

Krugman, P. (1991), Geography and Trade, Cambridge, MA, MIT Press.

Kuo, W., and Satchell, S. E. (2001), 'Global Equity Styles and Industry Effects: The Preeminence of Value Relative to Size', Journal of International Financial Markets, Institutions and Money, 11, 1-28.

Ormerod, P., and Mounfield, C. (2002), 'The Convergence of European Business Cycles 1978-2000', Physica A,307, 494-504.

Rouwenhorst, K.G. (1999), 'European Equity Markets and the EMU’, Financial Analysts Journal, 57-64.

Solnik, B., and Roulet, J. (2000), ‘Dispersion as Cross-sectional Correlation', Financial Analysts Journal, January/ February, 54-61.

Sontchik, S. (2004), 'Financial Integration of European Equity Markets', HEC University of Lausanne and FAME, mimeo.

Stulz, R. (1999), 'Globalization of Equity Markets and the Cost of Capital', Journal of Applied Corporate Finance, Fall, 8-25. 